\title{
A promoção de inclusão digital de estudantes da Educação de Jovens e Adultos (EJA) através da Extensão Universitária
}

\author{
José Vitor de Abreu Silva ${ }^{1}$, Rendrikson Soares ${ }^{1}$, Lucas Lima de Oliveira Garcia ${ }^{1}$, \\ Carlos Eugênio da Silva Rodrigues ${ }^{1}$, Waleska Davino Lima ${ }^{1}$, André Almeida Silva ${ }^{1}$ \\ ${ }^{1}$ Universidade Federal de Alagoas (UFAL) - Unidade Educacional Penedo \\ Av. Beira Rio S/N, Centro - 57200-000 - Penedo - AL- Brasil \\ vitorabreeus@gmail.com, rendrikson16@gmail.com, \\ garcia.lucas.lima@gmail.com, cpcarlos2611@gmail.com, \\ mariadavino@outlook.com, andre.almeida@arapiraca.ufal.br
}

\begin{abstract}
The advance of the Digital Technologies of Information and Communication (TDIC) brings transformations in the most diverse areas of knowledge, such as Education, which improves their teaching and learning processes. But the public school is still deficient in teaching these technologies. This article shows the authors' experience in the extension project "Technology and the public school: increasing the possibilities of teaching using basic computer equipment" whose goal was to digitally include students from Youth and Adult Education (EJA). The results show the importance of the role of university extension and the teaching of TDIC in public education, making the school more interactive and inclusive (digital and social).
\end{abstract}

Resumo. O avanço das Tecnologias Digitais da Informação e Comunicação (TDIC) traz transformações nas mais diversas áreas de conhecimento, como a Educação, que aperfeiçoa seus processos de ensino e aprendizagem. Mas, a escola pública ainda é deficiente no ensino dessas tecnologias. Este artigo mostra a experiência dos autores no projeto de extensão "A tecnologia e a escola pública: aumentando as possibilidades de ensino usando equipamentos básicos de informática" que objetivou incluir digitalmente estudantes da Educação de Jovens e Adultos (EJA). Os resultados mostram a importância da do papel da extensão universitária e do ensino das TDIC na educação pública, tornando a escola mais interativa e inclusiva (digital e socialmente).

\section{Introdução}

É notório que o uso das Tecnologias Digitais da Informação e Comunicação (TDIC) vem transformando o ambiente social como um todo. No âmbito educacional não é diferente. O impacto no que diz respeito ao ensino e aprendizagem é gradualmente visível, pois, com o avanço da tecnologia nas últimas décadas, discute-se cada vez mais a utilização de recursos da informática na educação.

Segundo Valente (2013), para que ocorra a implementação do computador na educação são necessários basicamente quatro ingredientes: o computador, o software educativo, o professor capacitado para utilizá-lo como meio educacional e o aluno, todos tendo a mesma importância nesse ambiente educacional. Com isso, é válido 
VIII Congresso Brasileiro de Informática na Educação (CBIE 2019)

Anais do XXV Workshop de Informática na Escola (WIE 2019)

ressaltar que a tecnologia não deve ser vista como máquina de ensinar, mas como uma ferramenta complementar que busca aperfeiçoar e transformar positivamente os resultados na qualidade de ensino.

Todavia, mesmo com todo o processo de expansão das TDIC, tendo maior visibilidade com a popularização do computador e da internet, sabe-se que ainda há uma grande quantidade de pessoas que não se encontram preparadas para o manuseio de tais ferramentas, sendo excluídas digitalmente do contexto social. Com base nisso, tornamse necessárias medidas que busquem viabilizar a inclusão desses indivíduos.

Um dos meios de inserção das pessoas no atual cenário tecnológico é a inclusão digital que pressupõe a possibilidade de produção e difusão do conhecimento e o acesso às ferramentas digitais para todos os indivíduos da sociedade, tendo como objetivo final a democratização da tecnologia. Atualmente, ao pensar nos avanços dessas tecnologias constata-se de imediato que, por conta da expansão nos últimos anos, a maioria das pessoas possuem computador, acesso à internet e outras maneiras de interagir com o mundo digital. Entretanto, ainda há muitos desafios a serem ultrapassados, tais como a pobreza que atinge grande parte da população e ocasiona a "exclusão" e afastamento dos indivíduos na realidade da sociedade informacional.

Em 2005, o Governo Federal instituiu no âmbito do Programa Inclusão Digital, o Projeto Cidadão Conectado - Computador para Todos, com o objetivo de promover a inclusão digital mediante a aquisição em condições facilitadas de soluções de informática constituídas de computadores, programas de computador neles instalados e de suporte e assistência técnica necessários ao seu funcionamento. Assim, o seu foco principal era expandir o número de brasileiros com acesso à internet.

Diante dos diversos artigos encontrados acerca do tema Informática básica na educação, realizado através de pesquisa bibliográfica, tal como a vivência dos discentes como educadores para alunos da Educação de Jovens e Adultos (EJA), o presente artigo constitui-se como um relato de experiência. Ademais, o artigo foi desenvolvido com base nas ações do projeto de extensão "A tecnologia e a escola pública: aumentando as possibilidades de ensino usando equipamentos básicos de informática" executado por docentes e discentes (colaboradores e membros do Programa de Educação Tutorial PET) da Unidade Educacional de Penedo da Universidade Federal de Alagoas (UFAL).

O principal objetivo do projeto de extensão é promover a inclusão digital dos educandos da EJA, através de aulas teórico-práticas, focando na informática básica. Assim, temas como a inicialização do computador, sistemas, história do computador, explorador de arquivos e equipamentos, usos da internet e o pacote do LibreOffice (Writer, Impress, Calc) foram vistos. Inicialmente buscou-se conhecer o perfil dos participantes, assim como seus conhecimentos prévios acerca da utilização de hardwares e softwares, a fim de que o conteúdo a ser ministrado fosse modelado ao público.

Serão discutidos ao longo do artigo concepções dos autores quanto ao processo de inclusão digital de jovens e adultos, será apresentado análise dos resultados obtidos, dando ênfase às dificuldades encontradas durante a realização das aulas ministradas e as contribuições para a inclusão digital e, consequentemente, social dos educandos participantes. Ressalta-se o papel fundamental da Universidade como transformadora da sociedade, sendo as ações de extensão um dos principais meios para a resolução ou amenização de problemas nas comunidades. 
VIII Congresso Brasileiro de Informática na Educação (CBIE 2019)

Anais do XXV Workshop de Informática na Escola (WIE 2019)

\section{TDIC na EJA: uma união para o aumento de potencialidades no ensino}

A partir da década de 1940 a Educação de Jovens e Adultos começou a se delinear e se constituir como política educacional, sendo reconhecido e criado o artigo 208 da Constituição Federal, possibilitando que a educação passasse a ser obrigatória no ensino público fundamental para aqueles que não tiveram acesso na idade própria.

A Educação de Jovens e Adultos é uma modalidade criada pelo Governo Federal que tem como principal alvo as pessoas que não tiveram acesso à educação convencional. Assim, permite que os alunos retomem os estudos e os concluam em um menor espaço de tempo, possibilitando sua qualificação para conseguir melhores posições no mercado de trabalho.

As disciplinas ofertadas na EJA seguem as diretrizes da Base Nacional Comum Curricular $^{1}$, ou seja, são as mesmas ministradas no ensino convencional. No ensino fundamental, os alunos têm acesso às disciplinas de Geografia, História, Matemática, Ciências, Educação Física, Artes, Inglês e Língua Portuguesa. No ensino médio, é a vez de terem acesso às disciplinas de Filosofia, Sociologia, História, Física, Química, Matemática, Ciências, Educação Física, Artes, Inglês e Língua Portuguesa. Visto que possuem as mesmas disciplinas do currículo tradicional, a diferença da EJA é que cada módulo pode ser concluído em apenas seis meses.

Para Lopes e Sousa (2012) a educação de jovens e adultos deve ir além da simples preocupação com a redução de números ou índices de analfabetismo. Ela deve ser direcionada à analise holística do educando, levando em consideração a sua cultura, sua interação com o mercado de trabalho e os aspectos previstos nas diretrizes curriculares da EJA que dispõem as funções de reparar, qualificar e equalizar o ensino.

Há diversos problemas presentes na educação brasileira, especialmente no que diz respeito a educação pública. Nessa perspectiva, Perrenoud (2000) afirma que a formação para as novas tecnologias está ligada a uma formação de julgamento, ampliando o senso crítico, o conceber de pensamento hipotético e dedutivo, ao passo que maximiza as faculdades de memorizar e classificar, contribuindo para a melhora da leitura e análise de textos e de imagens e trazendo novas possibilidades para a representação de redes, procedimentos e estratégias de comunicação.

Conforme o sistema educacional passa a utilizar as tecnologias digitais de informação e comunicação (TDIC) no processo de aprendizagem, há uma diminuição da exclusão digital, fazendo com que a educação vá além das salas de aula. Por isso, o computador pode trazer contribuições relevantes no contexto de ensino-aprendizagem. Para Moran (2012), a informatização está gerando uma explosão de saberes, logo, o aluno, importante elemento para a construção do saber, deve manter-se por dentro desse universo. Nota-se que a inclusão digital traz novas formas de comunicação e de interação com o meio, fato que ocasiona a inclusão social desses indivíduos.

É neste contexto que Silva (2001) defende o uso da tecnologia como ferramenta pedagógica, o que é de vital importância quando se nota o ganho que se teve nos últimos anos através da utilização de TDIC. Ferramentas foram empregadas em várias

\footnotetext{
${ }^{1}$ Base Nacional Comum Curricular. Disponível em: http://basenacionalcomum.mec.gov.br/. Acesso em: jun. 2019.
} 
VIII Congresso Brasileiro de Informática na Educação (CBIE 2019)

Anais do XXV Workshop de Informática na Escola (WIE 2019)

áreas de licenciaturas, como a matemática por exemplo, e podem potencializar o ensino dos saberes das mais diversas áreas, não ficando restritas a essa ou àquela disciplina.

É importante entender que oferecer ferramentas tecnológicas, seja de hardware ou de software, não é o único ponto no processo de ensino e aprendizagem. Logo, é importante oferecer formações aos professores que serão mediadores entre as TDIC e os alunos, potencializando a forma de como os conteúdos são passados e assimilados. $\mathrm{O}$ uso dessas tecnologias deve ajudar todos os setores das instituições educacionais fazendo com que o pensamento tecnológico ultrapasse os limites da sala de aula, contribuindo para a Educação como um todo.

Destaca-se, assim como apontam Soares et al (2015), que as habilidades dos estudantes só serão desenvolvidas com a adequada adaptação curricular aliada a processos didáticos e metodológicos que estejam em sintonia com o atual estágio e ritmo das mudanças tecnológicas. Essa mudança é vista de forma holística, na qual todos os atores da Educação deverão unir forças e para que a cultura educacional esteja voltada ao desenvolvimento de habilidades, através de um processo de construção individual e coletivizado do conhecimento mediado pelas TDIC.

\section{Materiais e Métodos}

O projeto de extensão aqui proposto teve início no primeiro semestre de 2019, sendo realizado na Unidade Educacional de Penedo (UE Penedo) da Universidade Federal de Alagoas (UFAL) em parceria com o Programa de Educação Tutorial (PET) dessa unidade. A equipe foi composta por 02 (dois) docentes, na condição de orientadores, e 09 (nove) discentes do curso de Sistemas de Informação da referida instituição de ensino, na qualidade de colaboradores e intermediadores das ações do projeto.

A princípio foi realizado um planejamento e sistematização das atividades. A realização das atividades foi organizada 05 (cinco) etapas: i) reunião com a direção da escola, a fim de explicar as diretrizes do projeto; ii) apresentação da importância do uso da informática na sociedade e divulgação do curso para os alunos da EJA; iii) levantamento do perfil dos alunos, organização de material didático e inscrições dos alunos; iv) formação dos discentes para aplicação do conteúdo; e v) análise dos resultados.

Nas duas primeiras etapas, a equipe executora do projeto teve contato com a direção e alunos da Escola Municipal Manoel Soares de Melo, bem como com a Secretária de Educação e Coordenadora da EJA. Salienta-se que essa escola é o polo da EJA na cidade de Penedo/AL. Nesse momento inicial foram apresentados os objetivos e diretrizes do projeto que teve aprovação e entusiasmo por parte do corpo docentes da escola. Logo após, a direção da escola sugeriu apresentação aos jovens e adultos alunos da EJA, por meio de uma palestra motivacional, com o intuito de expor a importância da informática na sociedade.

No terceiro momento foi realizado o planejamento das aulas, definindo qual sistema operacional e softwares seriam utilizados e qual o conteúdo cada discente da equipe ficaria responsável para ministrar. Logo após, foi definido a criação de uma apostila, tomando cuidado com a didática e linguagem utilizada, sendo produzida dentro do projeto. A apostila foi desenvolvida para ser utilizada pelos alunos da EJA, como material de apoio nas aulas, e distribuída no formato digital e impresso. A Figura 1 apresenta uma visão geral sobre o material didático desenvolvido, exibindo o conteúdo 
VIII Congresso Brasileiro de Informática na Educação (CBIE 2019)

Anais do XXV Workshop de Informática na Escola (WIE 2019)

referente à utilização do mouse e do teclado e um exercício pensado para a prática na formatação de arquivos de texto.

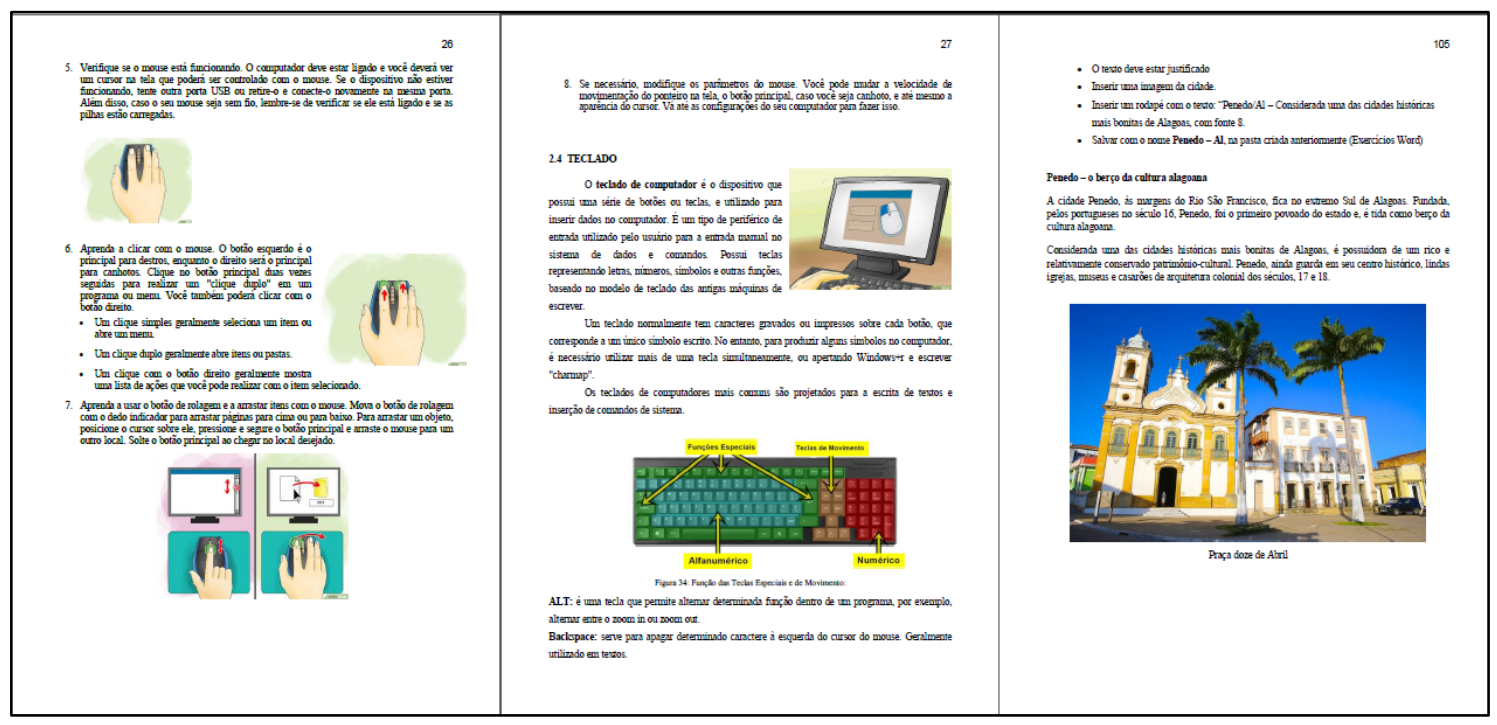

Figura 1. Recorte da apostila desenvolvida no projeto.

Em seguida, foi definido o período de duração do curso com um total de 10 aulas com 04 horas de duração cada aula, realizadas aos sábados no horário das 08h00min às $12 \mathrm{~h} 0 \mathrm{~min}$, para não comprometer o horário semanal de aulas noturnas, no laboratório de informática da UFAL/UE Penedo que contém 20 computadores e aparelho para projeção.

$\mathrm{Na}$ quarta etapa foram realizadas as supracitadas aulas, ministradas por um ou dois discentes colaboradores e tendo como auxiliares mais dois ou três discentes. A turma era composta por 20 alunos da EJA, selecionados pela direção da Escola Municipal Manoel Soares de Melo, com faixa etária entre 17 e 42 anos. Realizada a formação, a última etapa buscou analisar o resultado das aulas, observando as formas como elas procederam, o interesse e interação da turma, as dificuldades encontradas e percebeu-se no aprendizado das TDIC e inclusão digital dos alunos da EJA.

\section{Resultados e Discussão}

A partir da análise inicial do perfil dos participantes, das aulas ministradas e do convívio da equipe executora com os estudantes da EJA, notou-se que a maioria da turma nunca tinha tido contato com um computador (desktop), desconhecendo questões simples como segurar o mouse e posicionar corretamente as mãos para digitar. Além disso o déficit de conhecimento em informática ficou evidenciado em todos os alunos.

Diante da identificação dessas características, as aulas tiveram um direcionamento mais prático que teórico, fazendo com que a turma praticasse durante todos os conteúdos ministrados, que tiveram a seguinte ordem cronológica: história da computação e seus periféricos, focando na utilização do mouse e teclado; manipulação de arquivos e uso da internet; editor de texto, no qual foi utilizado o LibreOffice Writer, 
VIII Congresso Brasileiro de Informática na Educação (CBIE 2019)

Anais do XXV Workshop de Informática na Escola (WIE 2019)

por se tratar de um software gratuito; editor de slide, no qual foi usado o LibreOffice Impress; e o editor de planilhas, que foi utilizado o LibreOffice Calc.

No decorrer da apresentação do conteúdo programático na forma de aulas presenciais (Figura 2 e Figura 3), os alunos foram apresentados à utilização do computador para explorar aspectos voltados ao ensino e também a sua vida cotidiana. A exemplo disso destaca-se o conteúdo da utilização da Internet, voltando-se para à ampliação de seus conhecimentos e pela busca de informações que beneficiem a educação continuada, e a utilização do editor de texto para a preparação de atividades docentes.

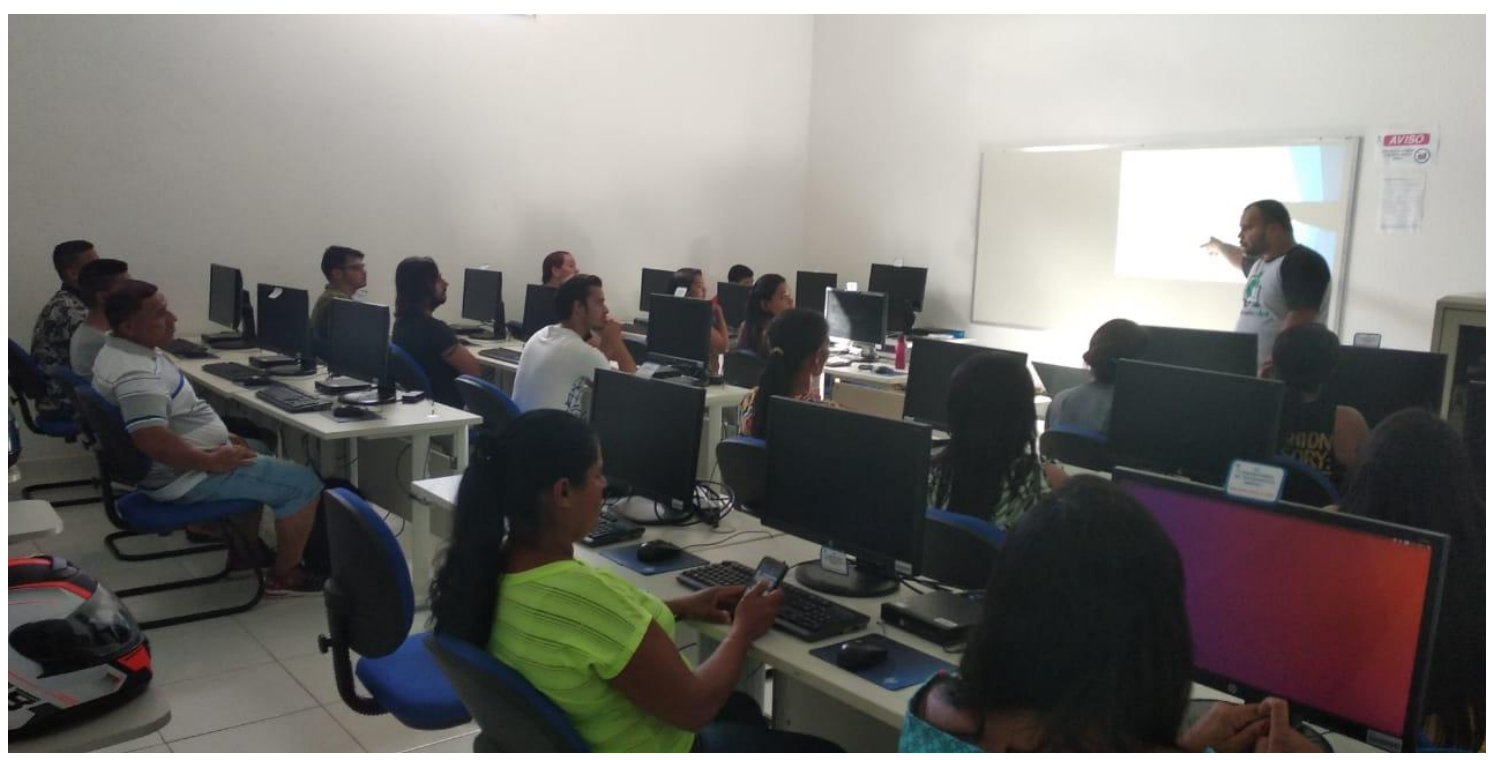

Figura 2. Aula sobre a história do computador.

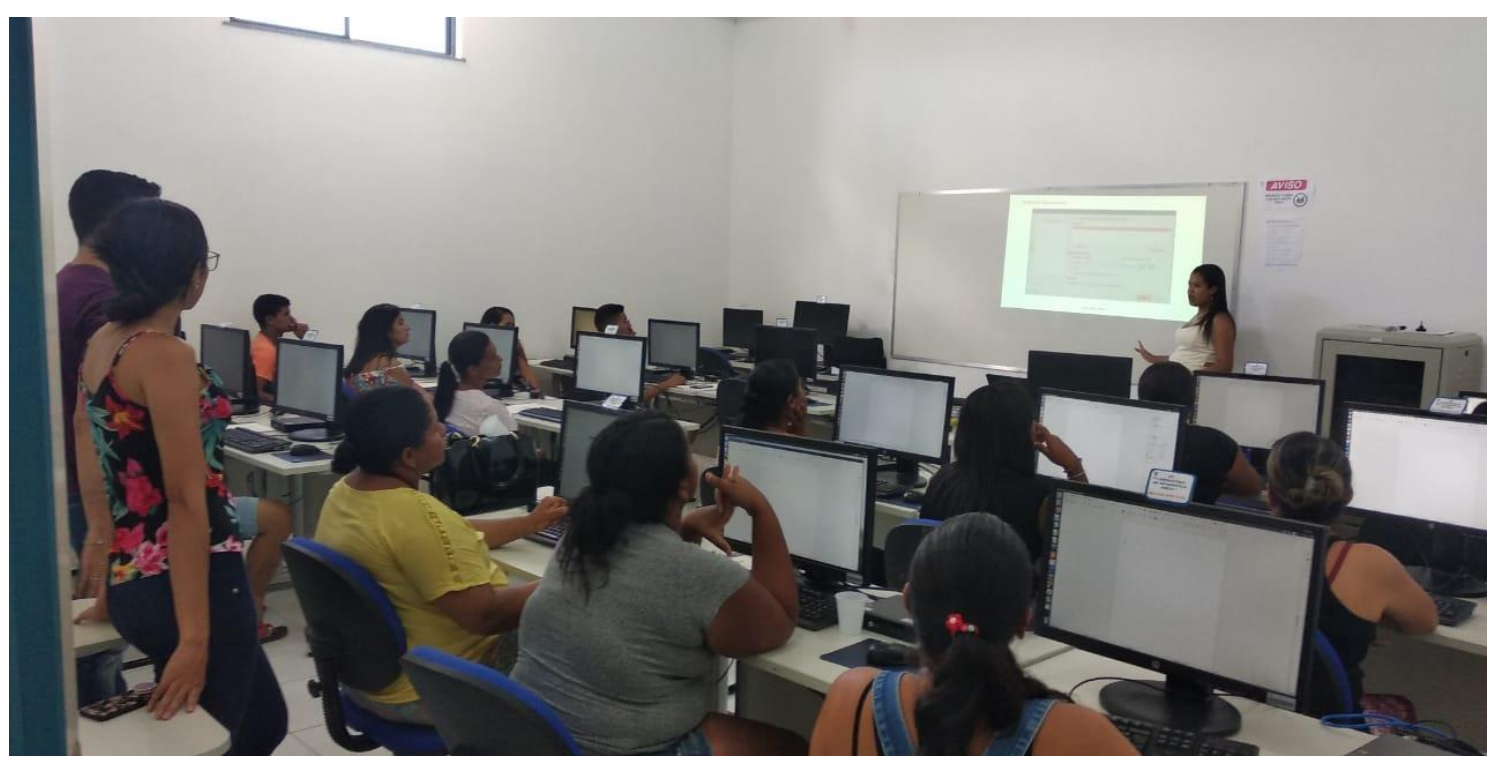

Figura 3. Aula sobre a utilização do LibreOffice Writer. 
VIII Congresso Brasileiro de Informática na Educação (CBIE 2019)

Anais do XXV Workshop de Informática na Escola (WIE 2019)

Destaca-se que os estudantes tiveram acesso aos softwares de escritório do LibreOffice, com ênfase naqueles que são usualmente utilizados: Writer (editor de texto), Calc (planilha eletrônica) e Impress (apresentador de slides). O Writer foi explanado de forma a exercitar a digitação, com aplicações de textos, bem como padronizando a formatação de acordo com as normas de trabalhos acadêmicos da Associação Brasileira de Normas Técnicas (ABNT). Também foi vista a inserção de imagens e formas no texto. As seguintes dificuldades foram percebidas: encontrar teclas, utilização de letras maiúsculas e uso da segunda e terceira função das teclas de acentuação e pontuação.

As aulas sobre o Impress focaram-se na criação de apresentações de modo simples e rápido, mostrando as maneiras de adicionar textos, gráficos, sons, vídeos e imagens, bem como efeitos de transição dos slides. Já o Calc, que é utilizado para trabalhar com planilhas eletrônicas, foi abordado de forma a manipular tabelas, e cálculos complexos, assim como uma tomada de decisão, dando ênfase à aplicação de fórmulas e funções. Perceberam-se também dificuldades quanto ao manuseio do teclado, além de certa lentidão para encontrar as funções dos softwares.

Diante das aulas ministradas percebeu-se a grande necessidade de formação quanto à utilização das tecnologias digitais no âmbito escolar, iniciando com a informática básica para então focar em TDIC específicas. O perfil do aluno da EJA traz peculiares quando comparado a outros estudantes: em regra, são pessoas que largam os estudos pela necessidade de trabalhar e manter suas famílias. Assim, são pessoas que não tiveram a educação formal na idade adequada e que ficaram à margem da educação digital, vista hoje como primordial para os contextos social e profissional.

Evidenciou-se grandes dificuldades na utilização do computador e suas ferramentas. Tarefas como digitar textos, baixar vídeos, fazer apresentações de slides e tabelas e acessar sites importantes voltados à informação e educação foram executadas pela primeira vez, pela maioria dos participantes, durante a execução das atividades deste projeto de extensão. Essa desconexão com as TDIC está diretamente associada à ausência de oportunidades em relação à instrução e acesso aos equipamentos de informática.

A seguir serão expostos comentários de dois participantes do curso, expostos na literalidade de como foram escritos. Essas falas são importantes para destacar o impacto das atividades do projeto de extensão aqui narrado, sob a perspectiva do seu público.

"Na minha opinião o curso está sendo muito importante pelo lado pessoal e futuramente profissional. As aulas do curso não tem o que reclamar, só elogiar todos os responsáveis por tornar o curso possível. Muito obrigado a todos por ter compartilhado seus conhecimentos conosco que levarei para toda vida e que me ajudará bastante" (Brenda Catarina Ramos).

"As aulas de informática foram bastantes úteis em relação à dúvidas que eu tinha sobre a informática, gostei de ser escolhida para participar do curso. Nas 
VIII Congresso Brasileiro de Informática na Educação (CBIE 2019)

Anais do XXV Workshop de Informática na Escola (WIE 2019)

realizações das minhas atividades vão ser muito úteis, tanto na área profissional, como na vida pessoal, e irá me ajudar também na área de emprego. Quero agradecer os professores que nos ensinou durante esse período de aprendizagem, vocês foram muito atenciosos, legais, gentis e principalmente pacientes. Espero que esse projeto continue favorecendo outras pessoas, assim como me favoreceu. Só tenho a agradecer” (Carla Regina Santos).

Enfim, ressalta-se que formações como as descritas neste artigo contribuem para a criação de um novo olhar sobre a realidade das TDIC na dinamização do ensino, entendendo que essas não podem ser negligenciadas, principalmente no contexto atual em que o aprendizado pode ser beneficiado pelas ferramentas tecnológicas. Observa-se ainda que levar o estudante a pensar sobre a importância da informática na sociedade e mostrar as formas de utilização das tecnologias é algo que ultrapassa a inclusão digital, isto é, nas ações realizadas ficou clara a inclusão social dos participantes.

\section{Conclusão}

Este artigo relatou as experiências dos autores no projeto de extensão "Aumentando as possibilidades de ensino através de ferramentas da informática básica para alunos da EJA", desenvolvido pela UFAL/UE Penedo, que pensou na inclusão de TDIC no ensino para fazer inclusão digital e social. As ações trouxeram muitos ganhos para todas as partes envolvidas nelas.

Em relação à participação da equipe executora (docentes e discentes da Universidade) percebeu-se grande engajamento que foi fundamental para chegar aos objetivos pretendidos com o projeto. Todas as etapas, iniciadas pela coleta de informações e visitas às escolas, passando pela confecção da apostila, até a execução das aulas, possibilitaram a vivência da realidade que, muitas vezes, não é percebida diante do estudo puramente teórico.

Para os estudantes da EJA que participaram do projeto, eles puderam conhecer o conceito teórico e prático da informática básica, descobrindo ferramentas e possibilidades até então desconhecidas, inserindo-se no mundo tecnológico e trazendo para si uma visão mais abrangente e inovadora de TDIC, tanto para atividades ligadas à escola quanto para atividades do cotidiano. Incluir digitalmente nos dias de hoje tem uma relação parecida com a da alfabetização, uma vez que as relações atuais estão em tão grande estágio de virtualização que é necessário conhecer o mínimo do mundo tecnológico.

Sendo assim, o objetivo proposto do projeto foi cumprindo, trazendo ganhos a todos os participantes das ações. Ressalta-se o papel da universidade, que se divide em ensino, pesquisa e extensão, sendo essa extensão que traz a comunidade para a universidade ou vice e versa. No mais, deixa-se claro que o Estado deve proporcionar os meios adequados para a inclusão digital dos seus cidadãos, não apenas levando equipamentos de informática para as escolas, mas criando políticas, focalizando a 
VIII Congresso Brasileiro de Informática na Educação (CBIE 2019)

Anais do XXV Workshop de Informática na Escola (WIE 2019)

formação de recursos humanos e trabalhando de maneira especial na inclusão das TDIC na Educação.

\section{Referências}

Lopes, S. P., Sousa, L. S. (2012) Eja: uma educação possível ou mera utopia?,, v1, p.120, 10 Set, 2012. Disponível em: https://pt.scribd.com/doc/105510649/EJA-UMAEDUCACAO-POSSIVEL-OU-MERA-UTOPIA. Acesso em: jun. 2019.

Moran, J. M., Massetto, M. T., Behrens, M. A. (2012) Novas tecnologias e mediações pedagógicas. Campinas, SP. Papirus.

Perrenoud, P. (2000) Dez novas competências para ensinar. Porto Alegre: Artmed.

Silva, M. (2001) Sala de aula interativa: a educação presencial e a distância em sintonia com a era digital e com a cidadania. In: CONGRESSO BRASILEIRO DA COMUNICAÇÃ̃O, 24., 2001, Campo Grande. Anais do XXIV Congresso Brasileiro da Comunicação, Campo Grande: CBC, set. 2001.

Soares, S. J., Bueno, F. F. L., Calegari, L. M., Lacerda, M. M., Dias, R. F. N. C. (2015) $\mathrm{O}$ uso das tecnologias digitais de informação e comunicação no processo de ensinoaprendizagem. Disponível em: http://www.abed.org.br/congresso2015/anais/pdf/BD_145.pdf. Acesso em: jun. 2019.

Valente, J. A. (2013) Diferentes usos do Computador na Educação, p. 1 - 10, 16 Nov. 2013. Disponível em: https://pt.scribd.com/doc/184576793/Diferentes-usos-doComputador-na-Educacao-valente. Acesso em: jun. 2019. 